\title{
Epidemiology of Scabies: Hospital Study in Brazzaville (Congo)
}

\author{
Bayonne Kombo ES ${ }^{1,2 *}$ and Kanga Okandze $\mathrm{A}^{2}$ \\ ${ }^{1}$ Faculty of Health Sciences, Marien Ngouabi University, Congo \\ ${ }^{2}$ Dermatology and Infectious diseases Department, Talangaï Reference Hospital, \\ Congo
}

*Corresponding author: Bayonne Kombo Edith Sophie, Faculty of Health Sciences/Marien Ngouabi University, PO Box 13423, Brazzaville, Congo, Tel: (242)05578 55 62; Email: sophiekbb@outlook.com

\section{Research article \\ Volume 4 Issue 4}

Received Date: October 20, 2019

Published Date: November 15, 2019

DOI: $10.23880 /$ cdoaj-16000194

\section{Abstract}

Introduction: Scabies is a contagious parasitic skin infestation caused by Sarcoptes scabiei variant hominis. Few white epidemiological data concerning scabies in Congo is available. The objective of this study was to describe the epidemiological aspects of scabies in Brazzaville (Congo).

Patients and methods: It was a retrospective study conducted from January 2016 to December 2018 in Talangai Reference Hospital in Brazzaville, Congo. Patients of any age received in outpatient dermatology for the diagnosis of scabies were included. The data was collected were age, sex, area of residence, season.

Results: Of 57 patients included, 29 were male and 28 females. Adults were $47.37 \%$ of cases (n=27) and children $52.03 \%$ of cases $(n=30)$. The scabies frequency was $2.3 \%$ of consultations cases. In adults and in children scabies accounted for $1.53 \%$ and $6.09 \%$ of reasons for consultation respectively. The mean age was 2.8 years (SD 2.6) in children and 34 years (SD 13.6) in adults. The age group between 0 and 5 years accounted for $42.1 \%$ of cases $(n=24)$. Rainy season was the consultation period in $75.44 \%$ of cases $(n=43)$.

Conclusion: Scabies is common among pediatric dermatoses. Its evaluation in the general population is necessary for a better representation of the extent of the disease.

Keywords: Scabies; Epidemiology; Dermatoses; Childhood; Congo

\section{Introduction}

Scabies is a contagious parasitic skin infestation caused by Sarcoptes scabiei variant hominis. It is a cosmopolitan disorder with prevalence in the world ranging from $0.2 \%$ to $71.4 \%$ [1]. Scabies is classified by the World Health Organization as a neglected tropical disease [2]. The disease is endemic in low-incomes and tropical countries, while in developed countries epidemics are restricted to hospitals, schools, care homes 
for elderly people and prisons [3]. Nevertheless, it remains a burden on populations in the regions where it is prevalent [4].

Despite the epidemic character of scabies in our geographic region, the epidemiological aspects are poorly described in Congo. In response to this data gap, we conducted a study whose objective was to describe the epidemiological aspects of scabies in Brazzaville (Congo).

\section{Patients and Methods}

This is a retrospective study conducted over a 3-year period from January 2016 to December 2018. The study setting was Dermatology and Infectious Diseases Department in Talangai Reference Hospital in Brazzaville, Congo. It is a first-reference district hospital for dermatological conditions.

The study population consisted of people received in outpatient dermatology. Patients of any age received for a human scabies were included. The diagnosis of scabies was based on history, clinical and parasitological criteria. Children were defined for an age of less than 16 years. The sampling was exhaustive from consultation records. The data was collected on an anonymous numeric form.
These were: age, sex, area of residence, season. The data processing was carried out with the Epi Infoß7 software.

\section{Results}

A total of 57 patients were included in the study. They were 29 male and 28 females. The sex ratio M/F was 1.03 . Adults were 27 (47.37\%) and children were 30 (52.03\%). All patients came from an urban area.

During the study-period 2251 people were seen in dermatology's consultation. The hospital frequency of scabies was $2.3 \%$. Scabies accounted for $1.53 \%$ of adults' reasons for consultation and $6.09 \%$ of children' reasons for consultation.

The mean age of the patients was overall 17.6 years (SD 18.42) with extremes ranging from 6 months to 65 years. The mode and median of ages were one and 7 years respectively. The mean age in children was 2.8 years (SD 2.6) and in adults 34 years (SD 13.6). The age group from 0 to 5 years (Figure 1) accounted for $42.1 \%$ of cases $(n=24)$.

Forty-three patients (75.44\%) consulted during the rainy season and 14 patients (24.56\%) during the dry season. The number of cases per year is shown in Figure 2.

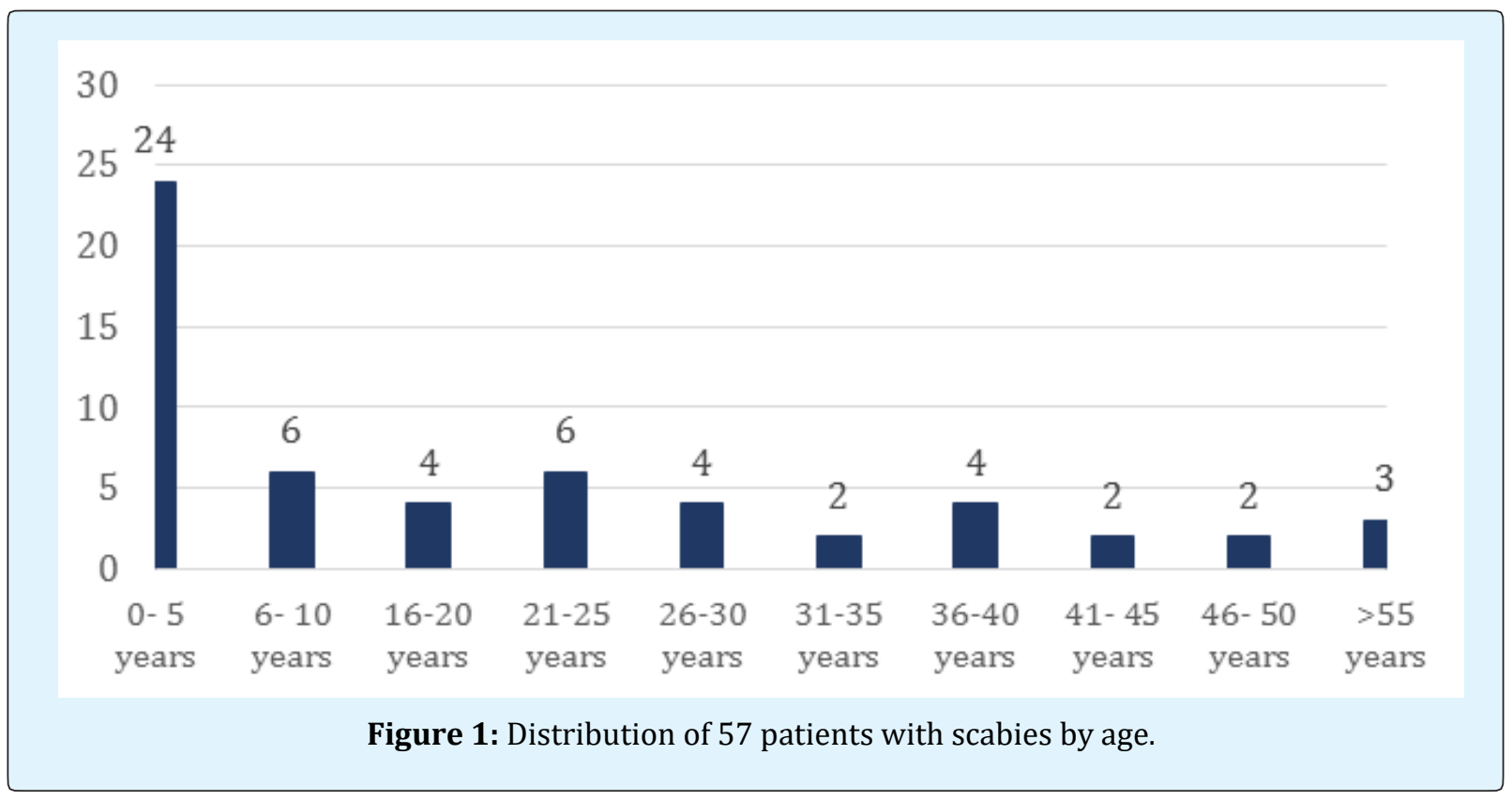

Bayonne Kombo ES and Kanga Okandze A. Epidemiology of Scabies: Hospital Study in Brazzaville (Congo). Clin Dermatol J 


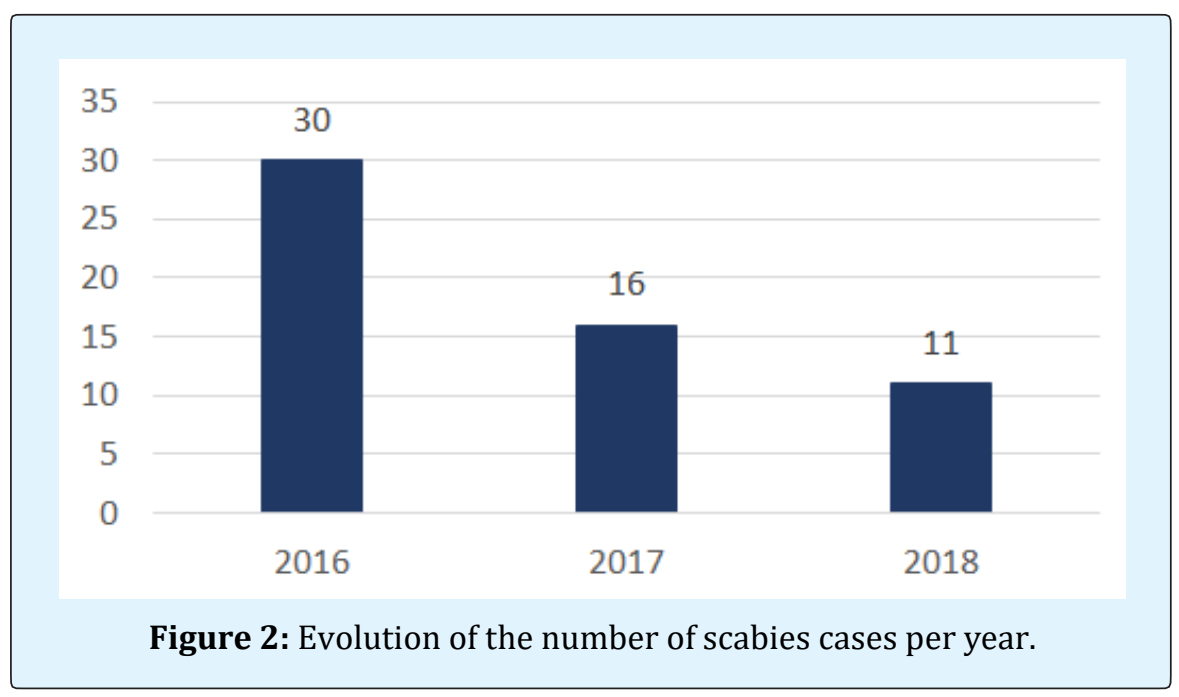

\section{Discussion}

This study is a preliminary work that aimed to provide insight into the epidemiology of human scabies in Congo. The choice of a district hospital as a setting for study is justified because it is the first-line health facility for dermatological problems. Indeed, scabies is a pruritic condition which can cause insomnia, very often motivates consultation in the health services. In our series, scabies occupies an important place in pediatric dermatology consultation by its prevalence of $6.09 \%$. Scabies is often regarded as disorders of resource-poor settings and particularly affect young children [5].

The transmission of scabies is most often carried out by direct and prolonged contact [6]. Close contact between children during games and school activities makes them frequent targets for contamination. Threequarters of scabies cases in our work occurred during the rainy season, characterized by strong heat. It has been established that dermatological infections such as human scabies increase after flooding [7]. Also, Sarcoptes scabiei can survive out of its human host several days in hot and humidity conditions $[8,9]$. This three-year work shows overall a decrease in the number of annual cases since 2016. This finding is encouraging compared to the measures implemented by the public authorities for both the early identification and treatment of cases of scabies.

\section{Conclusion}

Scabies is an important part of dermatoses in hospital setting, especially in childhood. Its evaluation in the general population is necessary for a better representation of the extent of the disease.

\section{References}

1. Romani L, Steer AC, Whitfeld MJ, Kaldor JM (2015) Prevalence of scabies and impetigo worldwide: a systematic review. Lancet Infect Dis 15(8): 960-967.

2. World Health Organization (2019) Neglected tropical diseases.

3. Mounsey KE, Murray HC, King M, Oprescu F (2016) Retrospective analysis of institutional scabies outbreaks from 1984 to 2013: lessons learned and moving forward. Epidemiol Infect 144(11): 24622471.

4. Karimkhani C, Colombara DV, Drucker AM, Norton SA, Hay R, et al. (2017) The global burden of scabies: a cross-sectional analysis from the Global Burden of Disease Study 2015. Lancet Infect Dis 17(12): 12471254.

5. Heukelbach J, Feldmeier H (2006) Scabies. Lancet 367(9524): 1767-1774.

6. Hicks M, Elston D (2009) Scabies. Dermatol Ther 22(4): 279-292.

7. Dayrit JF, Bintanjoyo L, Andersen LK, Davis MDP (2018) Impact of climate change on dermatological conditions related to flooding : update from the 


\section{Clinical Dermatology Open Access Journal}

International Society of Dermatology Climate Change Comittee. Int J Dermatol 57(8): 901-910.

8. Alter SJ, McDonald MB, Schloemer J, Simon R, Trevino J (2018) Common Child and Adolescent Cutaneous Infestations and Fungal Infections. Curr Probl Pediatr Adolesc Health Care 48(1): 3-25.
9. Arlian LG, Runyan RA, Achar S, Estes SA (1984) Survival and infectivity of Sarcoptes scabiei var. canis and var. hominis. J Am Acad Dermatol 11(2): 210215. 